\title{
Improvement of the Frequency Characteristics for RFID Patch Antenna based on C-Shaped Split Ring Resonator
}

\author{
Mahdi Abdelkarim \\ Physics Department \\ Faculty of Science, University of ElManar \\ Tunis, Tunisia
}

Seif Naoui

Physics Department

Higher Institute of Applied Science and Technology

Kasserine, University of Kairouan

Tunis, Tunisia

\author{
Lassad Larach \\ Physics Department \\ Faculty of Science, University of ElManar \\ Tunis, Tunisia \\ Ali Gharsallah \\ Physics Department \\ Faculty of Science, \\ University of ElManar \\ Tunis, Tunisia
}

\begin{abstract}
In this paper, we present a new technique for improving frequency characteristics and miniaturizing the geometric dimension of the RFID patch antenna that operates in the SHF band. This technique consists in implementing a periodic network based on a new model of a split C-ring resonator on the square slots of radiating rectangular patch antenna. The results of the simulation have proved that the proposed technique has an excellent radiation efficiency and size reduction compared to the reference patch antenna.
\end{abstract}

Keywords-Rectangular patch antenna; C-shaped split ring resonator; RFID reader antenna; metamaterials antenna

\section{INTRODUCTION}

RFID (Radio Frequency Identification) is an identification technology that has been appearing for military applications in 1950 [1], [2]. In 1990, RFID became prevalent in many industry services, such as access control, document tracking, distribution logistics, automotive systems, and animal tracking [3]-[6]. In these applications, the setup of a wireless communication link is crucial. So in such a case, we seek to increase the directivity, gain and minimize the size of the RFID antenna as possible to make the reader more compact and reduce the cost of the antenna.

There are several techniques to improve performance and miniaturize the dimension of UHF RFID antennas. The most well-known technique used in RFID is the inclusion of lefthanded metamaterials in the RFID antenna.

The metamaterials were proposed by Victor Viselago in 1968 [7]-[13]. They are artificial materials consisting of the network of periodic split ring resonators for obtaining a medium with negative refractive index. Since their appearance, we found a lot of studies that increasingly numerous on the implementation electromagnetism application which aims to improve performance and minimize RFID antenna.
In [14] the author provided a simple method to improve the performance of the rectangular patch antenna by using a novel Chiral Metamaterial (CM). This method consists of placing the substrate layer with metamaterials above the antenna. The study results show that for the antenna with the $\mathrm{CM}$, the gain increases from $4.84 \mathrm{~dB}$ to $7.46 \mathrm{~dB}$, by a rate of $2.6 \mathrm{~dB}$. In [15] a microstrip patch antenna based on an array of Complementary G-Shape Split Ring Resonator (CGSRR) is proposed to improve the gain and bandwidth of patch antenna. The measured results show that by owing to the presence of CGSRRs around the rectangular patch, the gain improves by $2.5 \mathrm{~dB}$ compared to the original antenna. Together the bandwidth of the antenna increases from $3.5 \%$ to $5.1 \%$. Moreover, in [16] the author developed a novel technique to reduce the size and increase the bandwidth of the rectangular patch antenna. It consists of implementing an array of complementary split ring resonators into the ground plane. The measured results proved that the proposed method able to reduce the size of patch antenna of $11.2 \%$ and improve the bandwidth of $202.6 \%$. In [17] the author presents a study on the performance and miniaturization of patch antennas with complementary metamaterials. Based on simulation result, the integration of a homogeneous and periodic array of complementary split ring resonators on the surface of the patch antenna has an interesting consequence on the antenna size and negative effect on the antenna gain. Therefore, according to the developed works, we can conclude if we seek to enhance the performance of the patch antenna, we lose the miniaturization of antenna dimension and it is the same thing in revere case.

Thus, in this paper, a new method based on the integration of novel C-Shaped split-ring resonator structure on the radiating patch antenna is proposed, studied and evaluated to miniaturize the dimension and improve the performance of the RFID patch antenna. The dimension of the proposed antenna 
is calculated according to [17] by using a microstrip line feed to operate at $2.4 \mathrm{GHz}$ RFID Band.

The paper is organized as follows, In Section 2 the design of the proposed SRR with C-Shaped technique is given and the simulation results were compared with simulation results of classic SRR at the same geometric forms in term of S11, surface currents, electric and magnetic fields, frequency band and effective permeability. In Section 3, the new technique based on the integration of an array of CSSR on the radiating surface of the RFID patch antenna is explained. Finally, in Section 4, the proposed structure is compared to the previous works and the traditional microstrip patch antenna in order to select the perfect technique [14]-[17].

\section{C-SHAPED SPLIT RING RESONATOR}

In this session, a novel C Shaped Split Ring Resonator (CShaped SRR) can give a left-hand medium (LHM) around its resonance frequency is presented. So, Based on the Split Ring (SRR) (Fig. 1(a)) which was introduced by Tang Chun Ming in 2010 [18], we will add in SRR two C-shaped implemented within the external ring for obtaining $\mathrm{C}$-shaped split ring resonator. Details of the C-Shaped SRR unit cell are described in Fig. 1(b). The proposed metamaterials was designed and fixed on Roger 5880 substrate with dielectric constant $\varepsilon_{r}=2.2$ and thickness $\mathrm{h}=1.6 \mathrm{~mm}$. The dimensions of C-Shaped SRR are: Lout $=7 \mathrm{~mm}, \operatorname{Lin}=6.5 \mathrm{~m}, \operatorname{Lin} 1=6 \mathrm{~mm}$, Gap $=0.5 \mathrm{~mm}$, Win $=0.5 \mathrm{~mm}$, Wout $=0.5 \mathrm{~mm}, \mathrm{~S}=0.5 \mathrm{~mm}$, $\mathrm{I}=5.4 \mathrm{~mm}$.

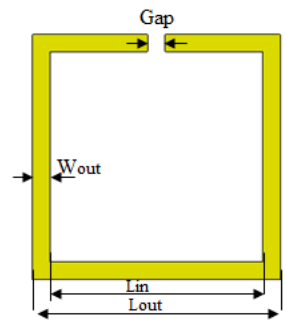

(a)

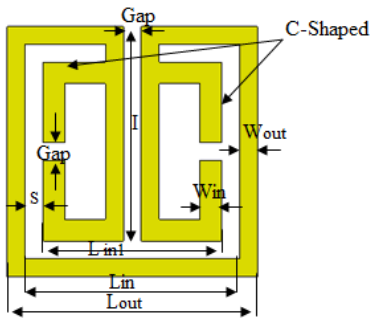

(b)
Fig. 1. Structure of (a) split ring resonator (b) Proposed C-shaped split ring resonator.

\section{A. Simulation and Results}

Two wave ports are set left-right faces of the box of proposed SRR to obtain the reflection and transmission coefficients. The effect of two C -Shaped on the reflection coefficient of the proposed cell is shown in Fig. 2. It is observed that by adding the $\mathrm{C}$ shaped in SRR, the resonance frequency shifts toward a lower frequency. So the proposed metamaterials illustrate at a frequency $2.6 \mathrm{GHz}$ with a transmission coefficient S21 of $-21 \mathrm{~dB}$. Therefore, this resonance frequency is slightly smaller than the original SRR by a difference arriving up to $2 \mathrm{GHz}$. This degradation at the resonant frequency due to the inductive and capacitive effect which appears in the metallic conductor lines lc and gab between the C-shaped. The relationship (1) [10] shows that if lc changes, the inductance $\mathrm{L}$ also changes and thus, there is a major gap change in resonant frequencies which can be interpreted from Fig. 2. Similarly, when the gap between the
C-shaped (2) is decreased, then the capacity $\mathrm{C}_{\text {gap }}$ also increases and thus according to (3) it is to be noted resonant frequencies must shift towards left.

$$
\begin{aligned}
& L=\frac{\mu_{0} h_{c}}{W} l_{c} \\
& C_{\text {gap }}=\varepsilon_{r} \varepsilon_{0} \frac{e}{g a p}
\end{aligned}
$$

Where,

hc: Conductor thickness [mm]

$\mu 0$ : permeability in the void $1.56 \times 10^{-6}\left[\mathrm{~m} \cdot \mathrm{Kg} \cdot \mathrm{S}^{-2} \cdot \mathrm{A}^{-2}\right]$

e: surface area $\left[\mathrm{mm}^{2}\right]$

Er: relative permittivity 3.2

E0: permittivity in the void $8.854 * 10^{12} \mathrm{~A} \cdot \mathrm{sV}^{-1} \cdot \mathrm{m}^{-1}$

$$
f=\frac{1}{2 \pi \sqrt{L C}}
$$

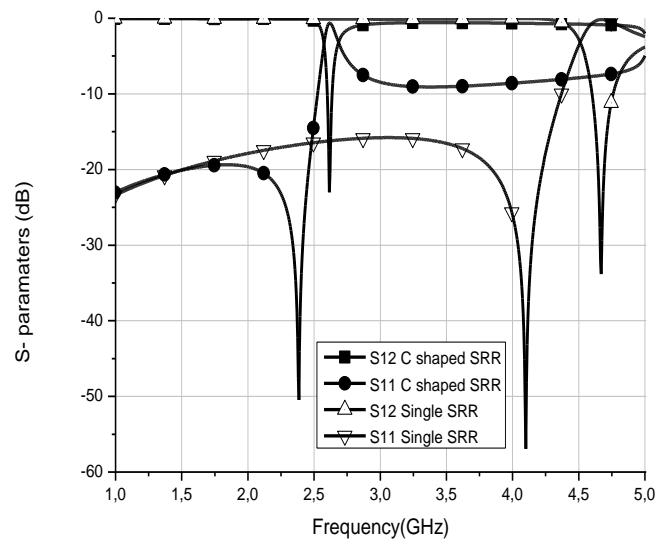

Fig. 2. Curve of the reflection and transmission coefficients produced by SRR and C- Shaped SRR structure.

$$
\mu_{e f f}= \pm \sqrt{\frac{\left(1+S_{11}\right)^{2}-S_{12}^{2}}{\left(1-S_{11}\right)^{2}-S_{12}^{2}}}
$$

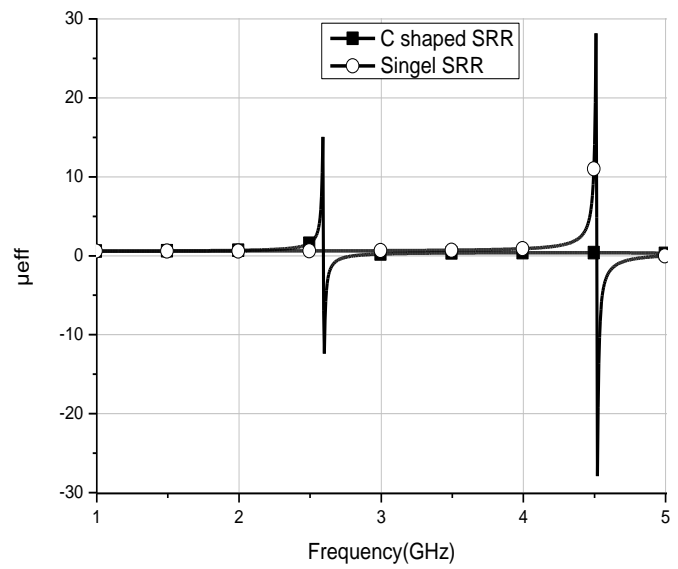


Fig. 3. The Effective permeability response of SSRR and C-shaped SRR.

Fig. 3 illustrates the curve of the real part of the effective permeability of C-shaped SRR and SRR cell. We can find that where the CSRR unit cell resonates, the permeability gives negative values ranging from zero to -12.5 .So for the frequency span $2.5-2.55 \mathrm{GHz}$. This negative region proves that the proposed metamaterial act as a Left-hand medium (LHM). Moreover, to have a deeper insight into the operation of the proposed CSRR, the distributions of the surface currents, magnetic field, and the electric field, are shown in Fig. 4(a)-4(c). All the distributions are presented out at the frequency which operates the proposed CSRR.

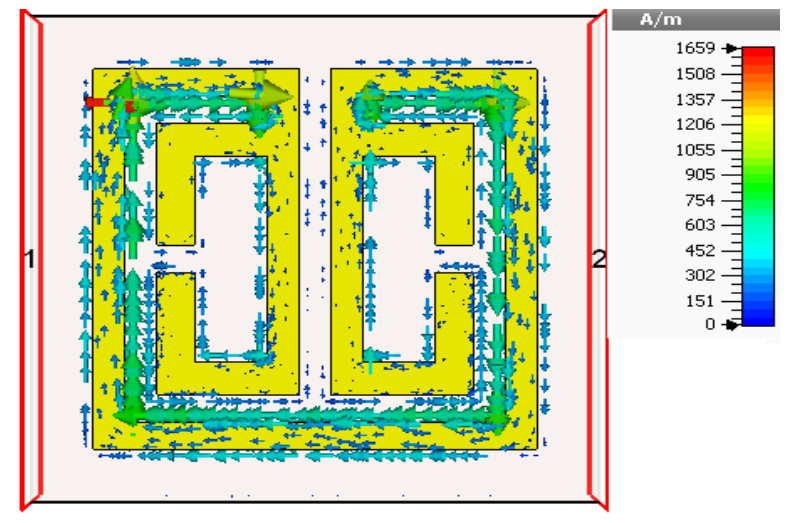

(a)

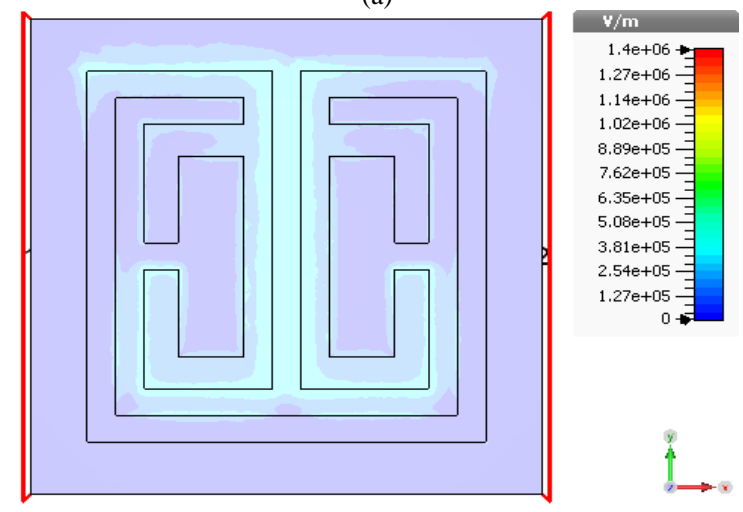

(b)
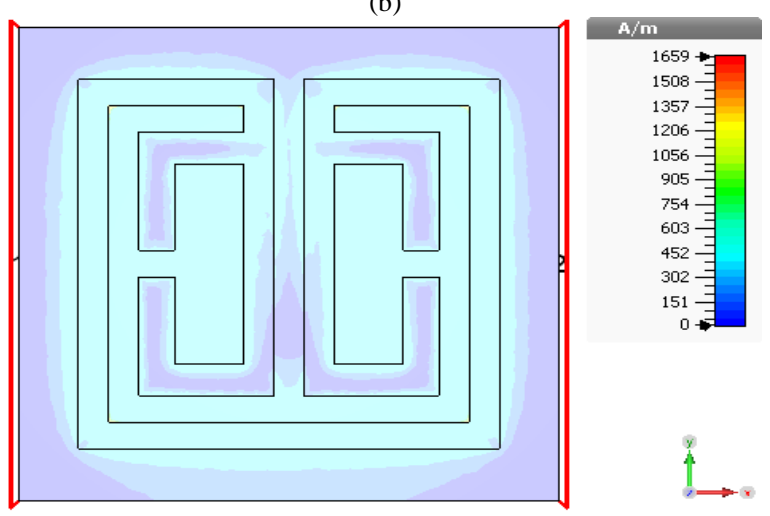

(c)

Fig. 4. Distributions of the (a) surface currents(b) electric field and (c) magnetic field in C-Shaped cell.
TABLE I. COMPARATIVE RESULTS BETWEEN THE SINGLE SRR AND CSHAPED SRR STRUCTURE

\begin{tabular}{|c|c|c|}
\hline $\begin{array}{l}\text { Characteristics of } \\
\text { metamaterials }\end{array}$ & SRR & C-Shaped SRR \\
\hline Frequency $(\mathrm{GHz})$ & 4.63 & 2.6 \\
\hline S21 [dB] & -33.5 & -24.4 \\
\hline S11 [dB] & -57 & -51 \\
\hline$\mu_{\text {eff }}$ & From 0 to -28 & From 0 to -12.5 \\
\hline FB [ MHz] & 85 & 40 \\
\hline Size $\% \lambda_{0}$ & $\lambda_{0} / 9.31$ & $\lambda_{0} / 16.48$ \\
\hline E (Electric field) & $7.4 \mathrm{e}^{05} \mathrm{~V} / \mathrm{m}$ & $1.4 . \mathrm{e}^{06} \mathrm{~V} / \mathrm{m}$ \\
\hline H(Magnetic field) & $566 \mathrm{~A} / \mathrm{m}$ & $1658 \mathrm{~A} / \mathrm{m}$ \\
\hline I(surface current) & $564 \mathrm{~A} / \mathrm{m}$ & $1659 \mathrm{~A} / \mathrm{m}$ \\
\hline
\end{tabular}

The comparison of the characteristics of the C-Shaped SRR with the classic SRR falling into the same geometry form is presented in Table I. It is shown that the distribution of surface current of the proposed C-Shaped SRR at the lower frequencies is higher than the higher resonance frequencies of Classic SRR. As seen in the comparison table, the C-Shaped SRR not only occupies a smaller size in comparison to classic SRR but also offers a high distribution of, Electric field and magnetic field. This is due to the fact of two C-Shaped on SRR.

\section{STUDY ON THE IMPROVEMENT OF THE RFID PATCH ANTENNA}

\section{A. Reference Patch Antenna}

The design structure of the reference patch antenna is shown Fig. 5. It [17] is employed with $50 \Omega$ micro-trip line feeding technique on a Rogers RT 5880 dielectric substrate with a thickness of $1.6 \mathrm{~mm}$, a permittivity $\varepsilon=2.2$ and a tangential loss $\delta=0.0009$.The antenna is designed for RFID applications in the frequency band from 2.4 to $2.485 \mathrm{GHz}$. The overall size of the antenna is $45 \times 38 \times 1.6 \mathrm{~mm} 2$, it is calculated according to (5) and (6) [17].

Patch Width:

$$
W=\frac{C}{2 f_{r}} \sqrt{\frac{2}{\varepsilon_{r}+1}}
$$

Patch Length:

With:

$$
L=\frac{C}{2 f_{r} \sqrt{\varepsilon_{r}}}-2 \Delta l
$$

$$
\begin{gathered}
\varepsilon_{\text {eff }}=\frac{\varepsilon_{r}+1}{2}+\frac{\varepsilon_{r}-1}{2}\left(\frac{1}{\sqrt{1+\frac{12 h}{W}}}\right) \\
\Delta l=0.412 h\left[\frac{\left(\varepsilon_{\text {eff }}+0.3\right)\left(\frac{W}{h}+0.264\right)}{\left(\varepsilon_{\text {eff }}+0.258\right)\left(\frac{W}{h}+0.8\right)}\right]
\end{gathered}
$$

The physical parameters of the transmission line are determined using "LineCalc" in the Advanced Design System (ADS) software. The Geometrical parameters of the reference patch antenna are shown in Table II: 
TABLE II. THE GEOMETRICAL PARAMETERS OF THE TRADITIONAL PATCH ANTENNA

\begin{tabular}{|l|l|l|}
\hline $\begin{array}{l}\text { Geometrical } \\
\text { parameters }\end{array}$ & Index & Value (mm) \\
\hline Patch Width & $\mathrm{W}$ & 45 \\
\hline Patch Lenth & $\mathrm{L}$ & 38 \\
\hline Feed line width & $\mathrm{W}_{\mathrm{T}}$ & 1 \\
\hline Feed line length & $\mathrm{L}_{\mathrm{T}}$ & 18 \\
\hline $\begin{array}{l}\text { Feed line end } \\
\text { length }\end{array}$ & $\mathrm{L}_{\mathrm{F}}$ & 5 \\
\hline Feed line end width & $\mathrm{W}_{\mathrm{F}}$ & 7.5 \\
\hline
\end{tabular}

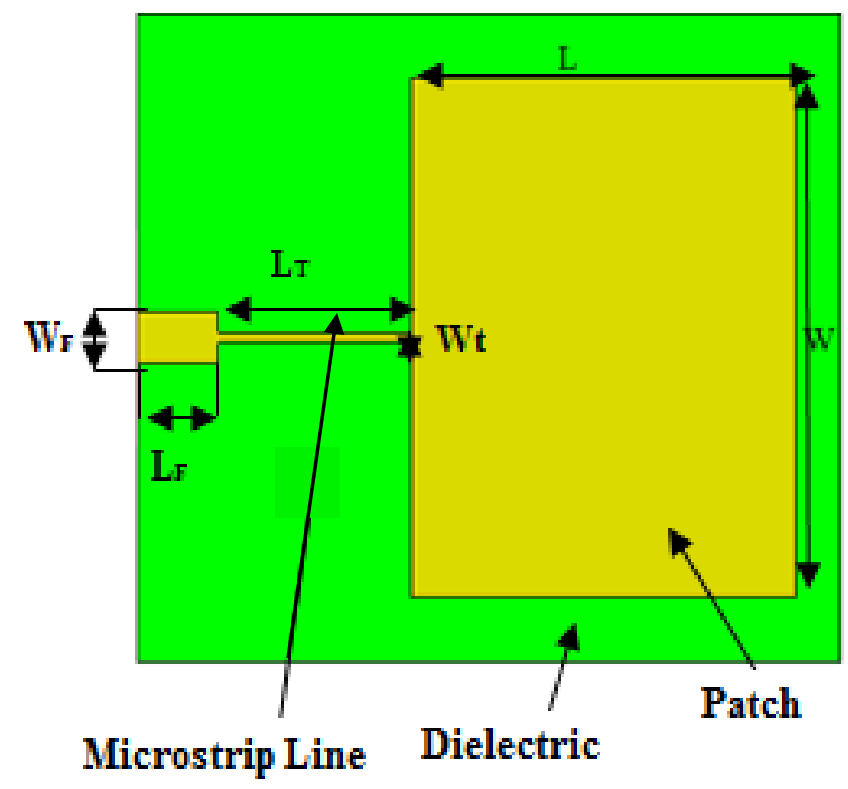

Fig. 5. Design of patch antenna reference.

\section{B. Inclusion of metamaterials in the environment of antenna}

In RFID applications, numerous works have been integrated of metamaterials in the environment of the patch antenna in order to reduce of its size and improve of its performances. To bind an RFID antenna together with metamaterials, two techniques have been proposed. The first one is to integrate an array of complementary split ring resonators into the ground plane of patch antenna [16]. This technique is able to miniaturize the dimension of the antenna due to change in input impedance, but contrariwise the antenna gain is still a major problem. The achievable gain with this technique is low about $3 \mathrm{dBi}$ at SHF Band, which has a negative influence on RFID performance such as read range. The other technique consists of placing the network of metamaterials around [15] or above [14] the patch antenna in order to improve the gain and bandwidth of the patch antenna, but this technique has some difficulties in antenna size. By the presence of metamaterials, the antenna becomes too big to attach to small devices. The main goal of the new technique is to increase the gain and miniaturize the dimension of patch antenna at the same time by using the proposed metamaterial.

The concept of the new technique is based on the integration of an array of CSSR on the radiating surface of the antenna, the objective is to increase the distribution of surface- current, Electric field and Magnetic field on this surface. The antenna composed of two parts: the periodic square slot part and the CSRR load part. The SRR loaded part consists of twenty CSRRs which are engraved vertically and horizontally on square slots of the patch antenna where the size of each square slot is $7.2 \times 7.2 \mathrm{~mm}^{2}$ (Fig 6(a)). The number of square slots is determined by the number of CSRR placed in the patch antenna. Moreover, to ensure a significant improvement in the performance of patch antenna, we must respect the constraint of periodicity during the integration of C-Shaped SRR in the antenna.

The network of C Shaped SRR must have a period $a<\frac{\lambda}{10}$

( $a$ depends on the size of C-Shaped SRR) along the radiating surface of the antenna. For the reason that the dimension of patch width is not the same than that of patch length, the periodic C-shaped SRR has a vertically edge-to-edge spacing of $\mathrm{a}_{1}=7.5 \mathrm{~mm}$ (Fig. 6(b)) and horizontally edge-to-edge spacing equal to $a_{2}=7.8 \mathrm{~mm}\left(a_{1}\right.$ and $a_{2}$ are slightly lower than the wavelength) for maximizing the number of C-Shaped SRR Cells around the patch antenna and ensure better performance improvement.

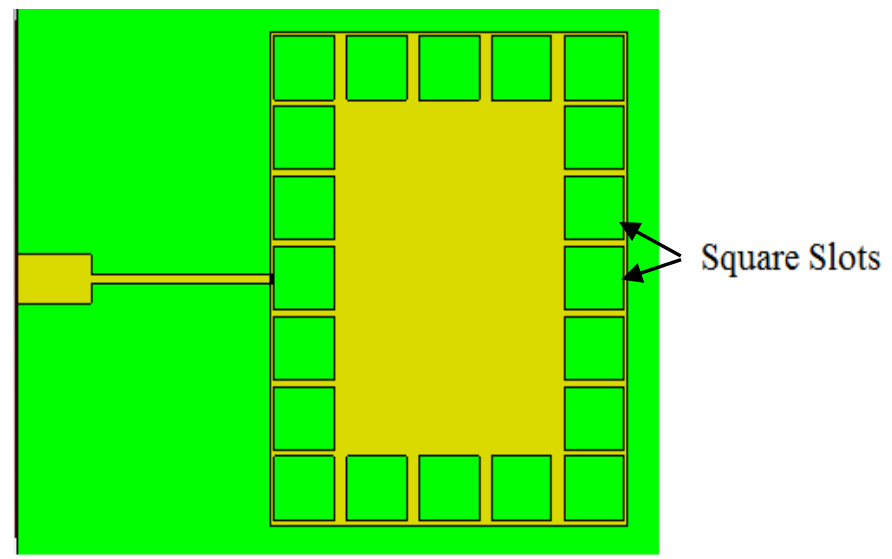

(a)

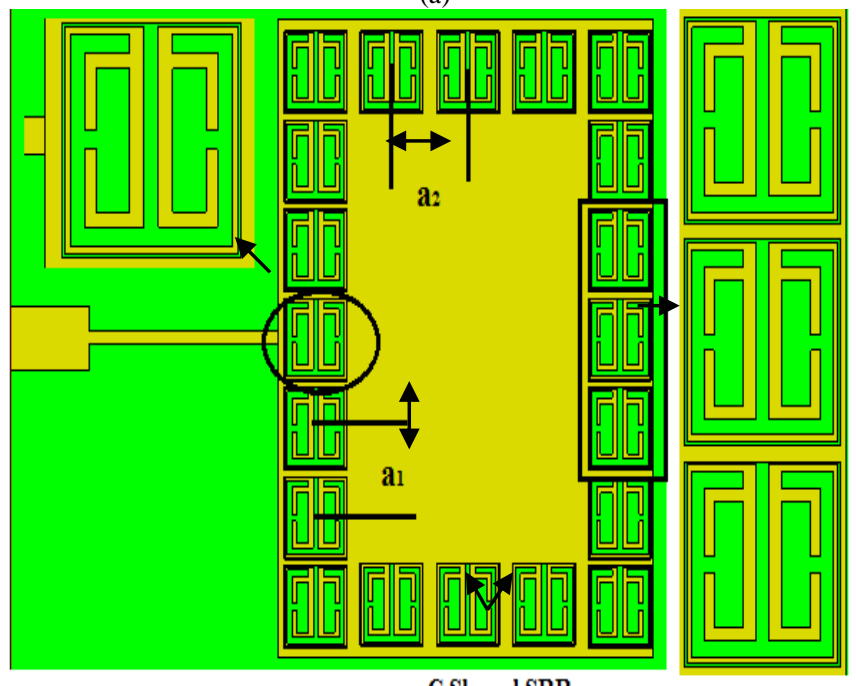

C Shaped SRR

(b)

Fig. 6. Design of Rectangular Patch antenna (a) with square slots (b) with C-shaped SRR Array. 


\section{Results and Discussions}

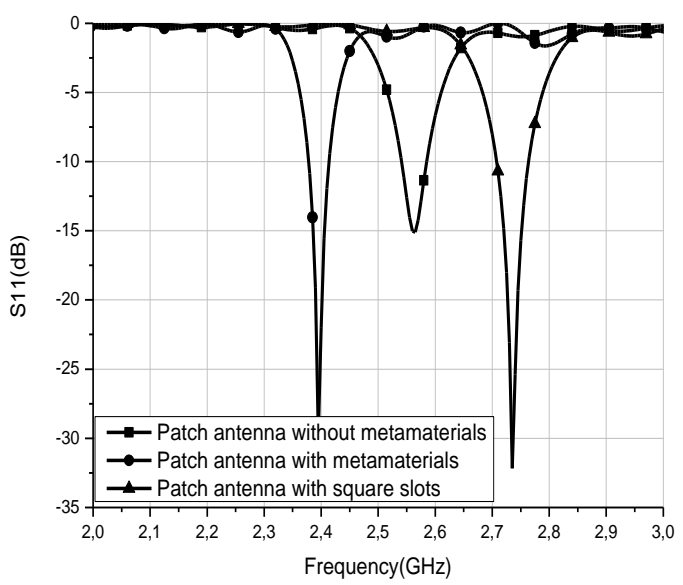

Fig. 7. Simulated S11 for the patch antenna without and with C-shaped SRR.

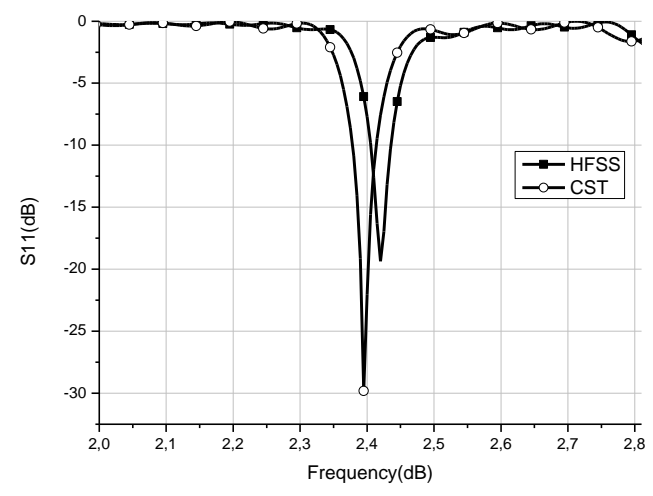

Fig. 8. Simulated S11 for the patch antenna with C-shaped SRR by HFSS and CST software.

Fig. 7 presents the simulated return loss in $\mathrm{dB}$ of the patch antenna in different cases: without metamaterials; with Square slots; with C-SRR. It can be observed that resonance frequency $\mathrm{S} 11$ is increased from $2.58 \mathrm{GHz}$ to $2.74 \mathrm{GHz}$ when we created a small square slots on the radiated part of patch antenna and downshifted from $2.74 \mathrm{GHz}$ to $2.4 \mathrm{GHz}$ with a better adaptation that reached $-30 \mathrm{~dB}$ when we integrated the proposed SRR on the slots by a degradation rate of $340 \mathrm{MHz}$ (this result is validated by HFSS and CST software as can be seen in Fig. 8). This degradation is understood due to the strong coupling of metamaterials which produce an inductive and capacitive effect. So we can say that the resonant frequency S11 is inversely proportional to the number of Cshaped SRR cells.

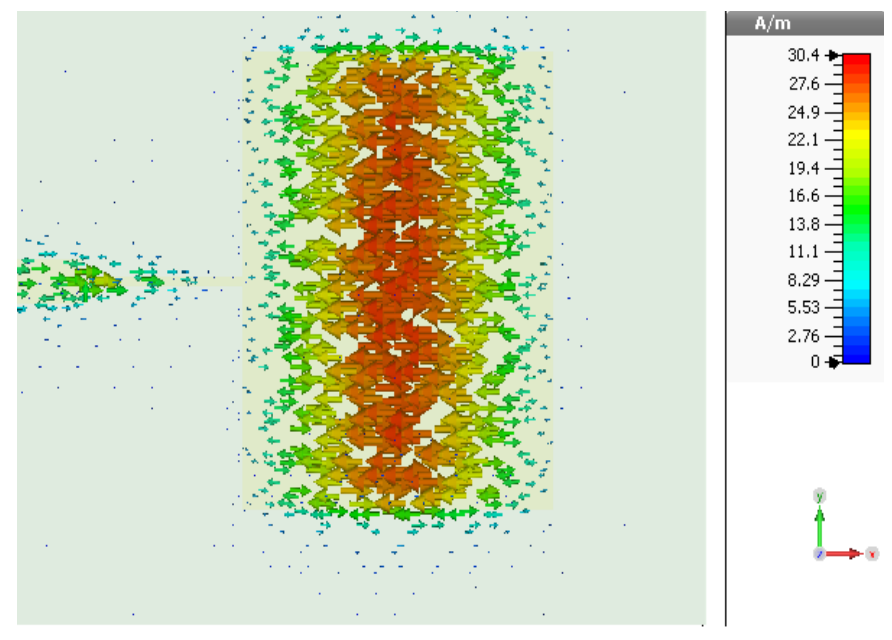

(a)

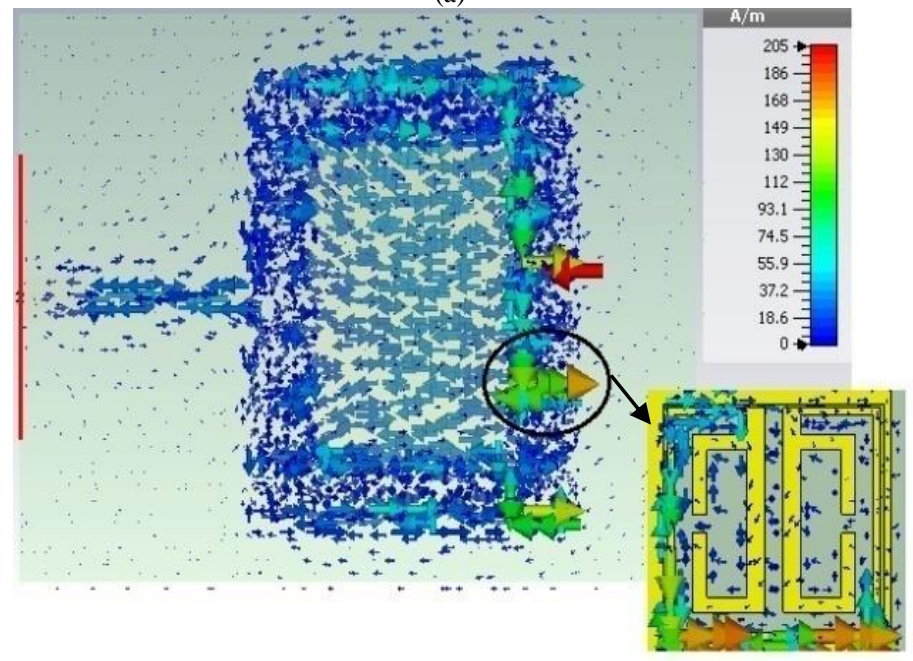

(b)

Fig. 9. Surface currents distribution in patch antenna (a) without $\mathrm{C}$-Shaped SRR at $2.59 \mathrm{GHz}$ (b) with C-shaped SRR Array at $2.4 \mathrm{GHz}$.

The simulated current distribution on the reference patch antenna is shown in Fig. 9(a). It is observed that the currents are asymmetrical and mainly distributed in the middle of the patch antenna. The surface current traveled through the reference patch antenna generates an Imax current of 30.4 $\mathrm{A} / \mathrm{m}$. By using the new technique on the patch antenna, the current is entering from the small square slots part and distributed in the CSRRs cell (Fig. 9(b)). The current density is changing rapidly at a radiating surface of the antenna at 2.4 $\mathrm{GHz}$. It has led to an Imax current of $205 \mathrm{~A} / \mathrm{m}$, which is slightly higher to that current distribution of patch antenna without the use of C-SRR. So, we can conclude that the CSRRs part makes a vital contribution to the current movement. 

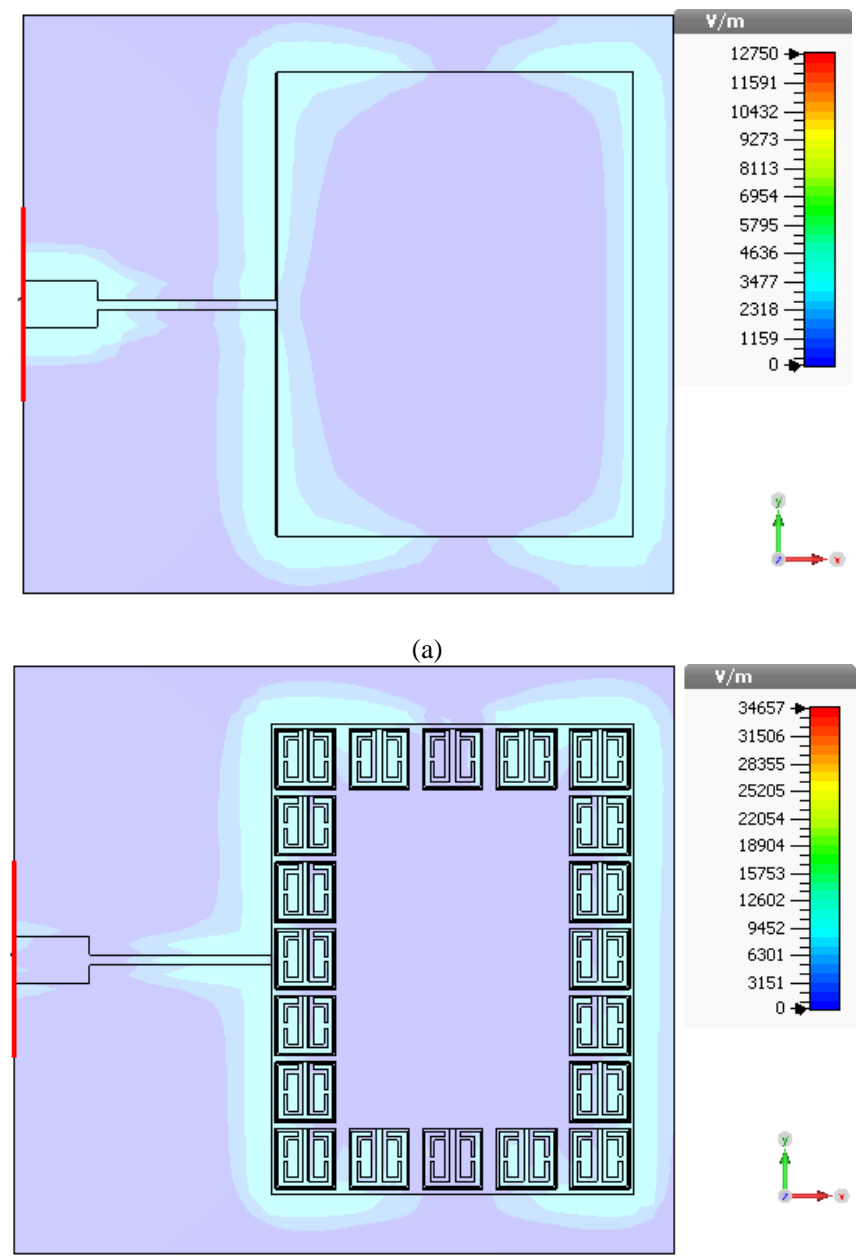

28355 手

(b)

Fig. 10. Electric field distribution in patch antenna (a) without $\mathrm{C}$-Shaped SRR at $2.59 \mathrm{GHz}$ (b) with C-shaped SRR Array at $2.4 \mathrm{GHz}$.
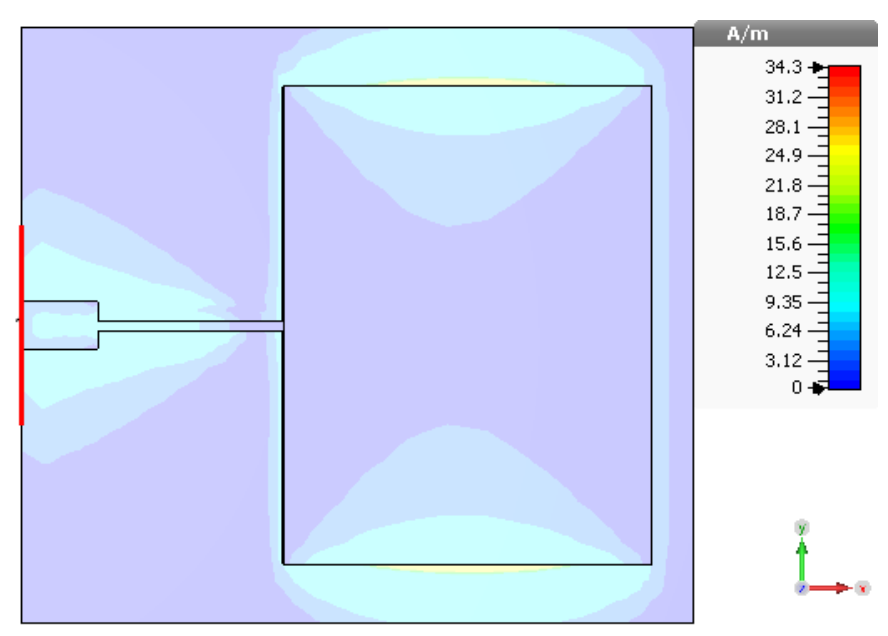

(a)

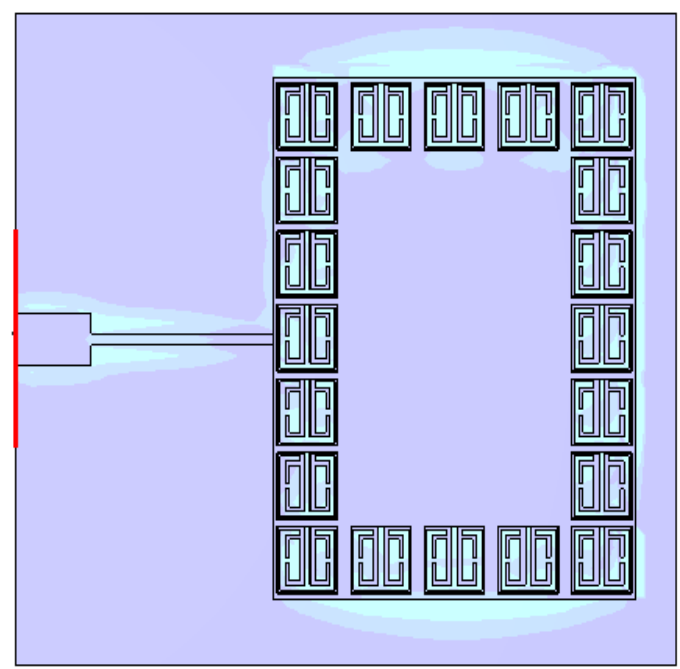

$\mathrm{A} / \mathrm{m}$

(b)

Fig. 11. Magnetic field distribution in rectangular patch antenna (a) without $\mathrm{C}$ -Shaped SRR at $2.59 \mathrm{GHz}$ (b) with C-shaped SRR Array at $2.4 \mathrm{GHz}$.

Fig. 10 and 11 show the Peak values of the electric field and the magnetic field in the patch antenna with and without the use of C-shaped SRR at the frequency of 2.59 and $2.4 \mathrm{GHz}$. It is clear that at low frequencies $(2.4 \mathrm{GHz})$ the Electric and magnetic fields are changed and the peak values are higher as compared with the peak values of reference patch antenna at $2.59 \mathrm{GHz}$. So, we can conclude that the proposed metamaterial is helping to increase the distribution of electric and magnetic fields of the patch antenna.

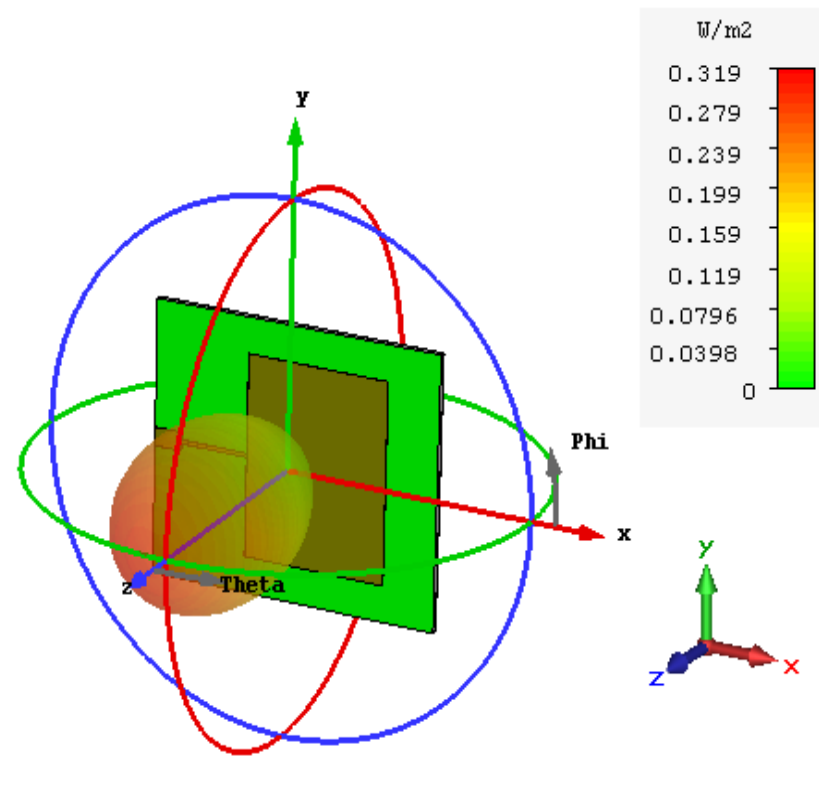

(a) 

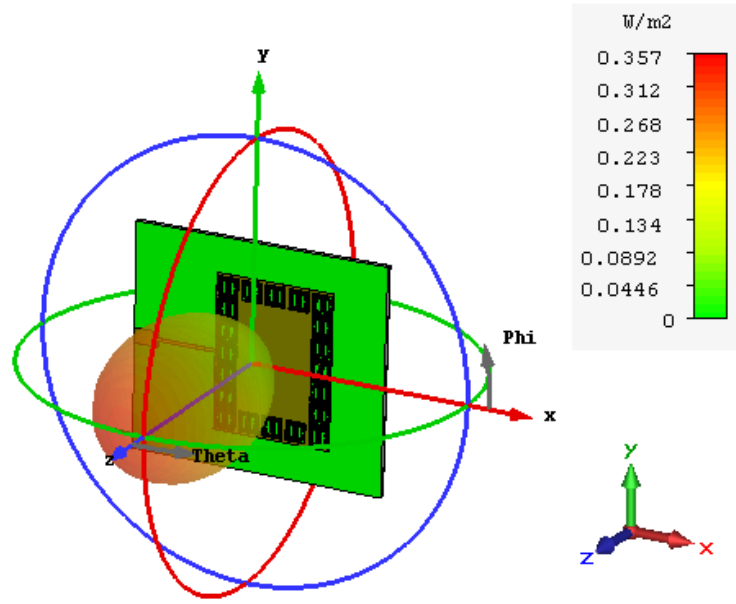

(b)

Fig. 12. 3D Simulated power pattern for patch antenna (a) without the use of C-SRR (b) with C-SRR.

Moreover, the increase in the electric field and the magnetic field acts directly on the total power of the antenna. Fig. 12 presents the radiated power field of the patch antenna with and without the use of $\mathrm{C}$-Shaped split ring resonator. It can be seen that the metamaterials antenna produces a total emitted power field $\mathrm{P}$ equal to $0.357 \mathrm{~W} / \mathrm{m} 2$ that is higher to that provided by the patch antenna alone.

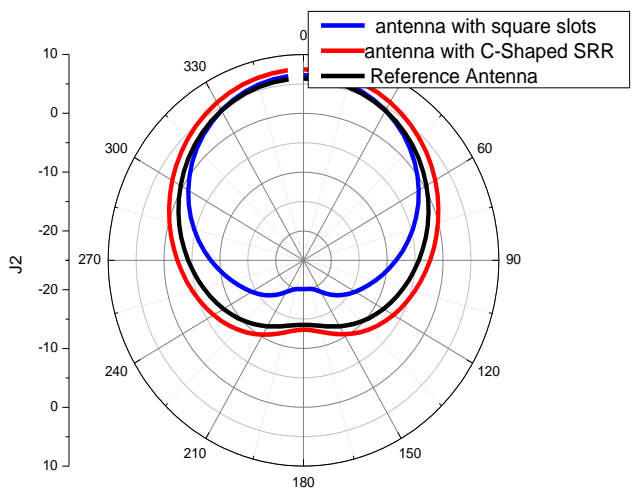

(a)

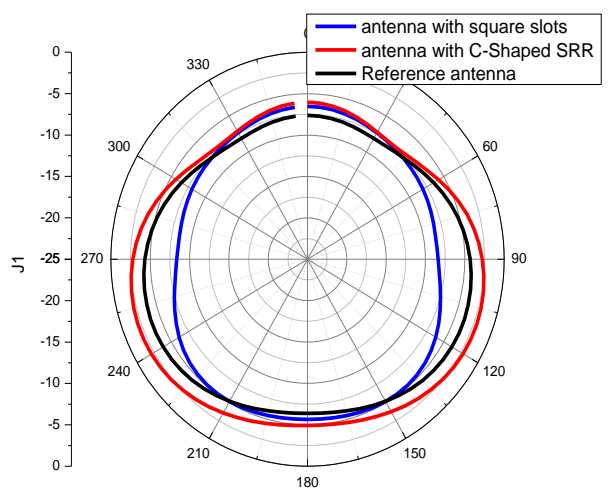

(b)

Fig. 13. Simulation Radiation pattern of the patch antenna with and without C-Shaped SRR (a) E plane (b) H-plane.
Fig. 13 shows the simulated E-plane and $\mathrm{H}$-plane radiation patterns of the antennas without metamaterials; with Square slots; with C-shaped SRR. It is observed that C Shaped SRRloaded antenna presents gain of about $6.91 \mathrm{~dB}$ in the whole working band $(2.39 \sim 2.43 \mathrm{GHz})$, which is about $1 \mathrm{~dB}$ more than the unloaded one. Consequently, the antenna efficiency in the use of C-Shaped SRR increases to $94 \%$ with a rate of improvement that exceeds $14 \%$ compared to the reference antenna (Fig. 14).

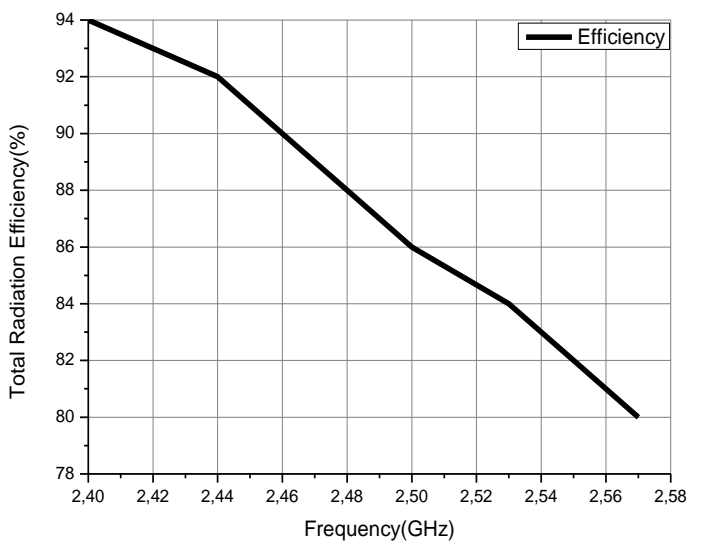

Fig. 14. Radiation efficiency curve of the proposed patch antenna.

The comparative table between the antenna patch without and with C-Shaped SRR is shown in Table III. From the results obtained, it shows that the C-Shaped SRR is successfully utilized to increase the gain and miniaturize the dimension of the RFID patch antenna that operates in the SHF band $(2.4-2.485 \mathrm{GHz})$.

TABLE III. COMPARATIVE RESUlts BETWEEN THE ANTENNA PATCH WITHOUT AND WITH C-SHAPED SRR

\begin{tabular}{|l|l|l|}
\hline $\begin{array}{l}\text { Characteristics } \\
\text { of antennas }\end{array}$ & $\begin{array}{l}\text { Patch antenna } \\
\text { without } \\
\text { metamaterials }\end{array}$ & $\begin{array}{l}\text { Patch antenna } \\
\text { with C-shaped } \\
\text { Array }\end{array}$ \\
\hline $\begin{array}{l}\text { Resonance } \\
\text { Frequency }\end{array}$ & $2.57 \mathrm{GHz}$ & $2.4 \mathrm{GHz}$ \\
\hline S11 & $-15.5 \mathrm{~dB}$ & $-29 \mathrm{~dB}$ \\
\hline Electric field & $12750 \mathrm{~V} / \mathrm{m}$ & $34657 \mathrm{~V} / \mathrm{m}$ \\
\hline Magnetic field & $34.3 \mathrm{~A} / \mathrm{m}$ & $187 \mathrm{~A} / \mathrm{m}$ \\
\hline Surface current & $30.4 \mathrm{~A} / \mathrm{m}$ & $165 \mathrm{~A} / \mathrm{m}$ \\
\hline Total Power & $0.319 \mathrm{~W} / \mathrm{m}^{2}$ & $0.357 \mathrm{~W} / \mathrm{m}^{2}$ \\
\hline Gain & $5.92 \mathrm{~dB}$ & $6.91 \mathrm{~dB}$ \\
\hline Directivity & $7.32 \mathrm{dBi}$ & $7.34 \mathrm{dBi}$ \\
\hline n & $80 \%$ & $94 \%$ \\
\hline \multicolumn{1}{|c|}{ Size } \\
reduction & $* *$ & $3 \%$ \\
\hline
\end{tabular}

\section{Theoretical Demonstration}

As we stated in the previous part (Results and discussions), the integration of a periodic network based on a new model of a split C-ring resonator on the square slots of radiating rectangular patch antenna increase the surface current distribution $I_{\max }$ and help to enhance the distribution of electric $E_{\max }$ and magnetic $H_{\max }$ fields which acts directly on 
the total power of the antenna and consequently has a positive influence on the antenna frequency characteristics in term of gain; radiation efficiency; S11 adaptation.

Let us now discuss the theoretical study on the improvement of the RFID patch antenna. The currents $\mathrm{I}_{0}$ and the charges $\mathrm{Q}_{0}$ are the primary sources of the radiated electric and magnetic fields whose propagation of the wave is in function of $\frac{\exp (-i \beta r)}{r}$. Such as " $r$ " presents the maximum distance of radiation and $\beta$ indicates the phase constant that is defined by the following relation:

$$
\beta=\frac{2 \pi}{\lambda}
$$

The imbalance that occurs in the distribution of the charges $\mathrm{Q}_{0}$ negative / positive and the current $\mathrm{I}_{0}$ traversing an antenna, allows the creation of the electric and magnetic fields delivered by the radiating element. As a result, we get electromagnetic waves propagated in space by forming a radiation pattern. The radiated electric $\mathrm{E}_{\mathrm{rad}}$ and magnetic $\mathrm{H}_{\mathrm{rad}}$ fields have a direct influence on the total radiated power density, which in turn results in this density being as high as possible because it correlates proportionally with the antenna performance.

The propagation of electric and magnetic fields in space can be determined by solving the following Maxwell equations [20]:

$$
\left\{\begin{array}{l}
\operatorname{div} \vec{E}=\frac{\rho}{\varepsilon} \\
\operatorname{div} \vec{B}=0 \\
\operatorname{rot} \vec{E}=-\mu \frac{d \vec{H}}{d t} \\
\operatorname{rot} \vec{H}=\sigma \vec{E}+\varepsilon \frac{d \vec{E}}{d t}
\end{array}\right.
$$

So now, it is possible to determine any primary source characterized by a volume distribution of the current Iv and charge Qv at a point M by the vector potential $\vec{A}(14)$ and the scalar V (15) which are defined by the following relations [21], [22]:

$$
\left\{\begin{array}{c}
\vec{A}(M)=\frac{\mu}{4 \pi} \int_{V} \vec{I} \frac{\exp (-i \gamma r)}{r} d v \\
V(M)=\frac{1}{4 \pi \varepsilon} \int_{V} Q \frac{\exp (-i \gamma r)}{r} d v
\end{array}\right.
$$

According to these two parameters $\vec{A}$ and $\mathrm{V}$, we can determine the radiated electric $\mathrm{E}_{\mathrm{rad}}(15)$ and magnetic $\mathrm{H}_{\mathrm{rad}}(16)$ fields and total emitted power density $p$ (18) [18], [19].

$$
\begin{aligned}
& \left\{\begin{array}{l}
\vec{E}_{r a d}=\frac{-d \vec{A}}{d t}-g r a \vec{d} V \\
\vec{H}_{r a d}=\frac{1}{\mu} \operatorname{rot} \vec{A}
\end{array}\right. \\
& \left\{\begin{array}{l}
p(r, \theta, \varphi)=\left|E_{r a d}\right| \times\left|H_{r a d}\right|=\frac{\left|E_{r a d}\right|^{2}}{Z_{m}} \\
Z_{m}=\frac{\left|E_{r a d}\right|}{\left|H_{r a d}\right|}
\end{array}\right.
\end{aligned}
$$

With Zm: Impedance of the medium propagating by the electromagnetic wave.

Finally, we can calculate the Radiation diagram in power $D$ (Eq19) and the Gain in power $G$ (Eq20) according to the expression of total radiated power density $p$ using the following equations [18], [19]:

$$
\left\{\begin{array}{c}
D(\theta, \varphi)=\frac{P(\theta, \varphi)}{P_{\max }}=\frac{4 \pi r^{2} p(\theta, \varphi)}{P\left(\theta_{0}, \varphi_{0}\right)} \\
G(\theta, \varphi)=\frac{P(r, \theta, \varphi)}{P_{\text {isotropie }}}=\frac{4 \pi r^{2} p(r, \theta, \varphi)}{\int_{0}^{2 \pi} d \varphi \int_{0}^{\pi} r^{2} \operatorname{Sin}\left(\theta_{0}\right) p\left(r, \theta_{0}, \varphi_{0}\right) d \theta}
\end{array}\right.
$$

\section{COMPARATIVE STUdY}

In the final section, a comparison made between the proposed structure and others realized works in order to select the perfect technique. The reflection coefficients (S11) curves of the antennas corresponding to different types of loading structures are given in Fig. 15. It is possible to observe that by using the new technique the resonating frequency of the antenna shifts from $2.57 \mathrm{GHz}$ to $2.4 \mathrm{GHz}$, thus obtaining a miniaturization of $3 \%$, and an improvement with $1 \mathrm{~dB}$ compared to the reference antenna which means that the proposed technique does not only have the influence of the radiation pattern but also on the resonant frequency. From previous works [14]-[17], it is observed that better miniaturization has been achieved using the technique of implementing an array of complementary split ring resonators into the ground plane. This technique has a better compact size compared to the other existing structure by $30 \%$ size reduction, but the negative effect on the antenna performance. Similarly, in case of the antenna with CSRR, the reflection coefficients (S11) decrease and also shift towards the lower frequency with a reduction in antenna performance.

Fig. 16 shows a comparison of the radiation patterns of the antenna with and without metamaterials taken at 2.57 $\mathrm{GHz}, 2.58 \mathrm{GHz}, 1.9 \mathrm{GHz}, 2.32 \mathrm{GHZ}$ and $2.4 \mathrm{GHz}$ for both $\mathrm{E}$ plane and $\mathrm{H}$ plane. We can find that the strong gain in the whole working band is obtained by the technique of placing the substrate layer with Chiral Metamaterial (CM) above the antenna. The results demonstrate that $2 \mathrm{~dB}$ gain enhancement is achieved compared to the reference antenna, but 
contrariwise the antenna size still a major problem. The frequency Characteristics comparison of the proposed antenna with the techniques used in [15]-[17] is presented in Table IV.

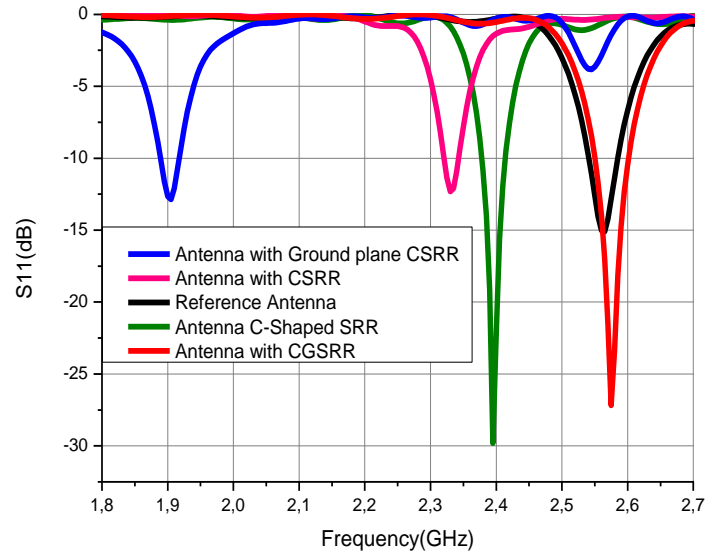

Fig. 15. Comparative analysis of S11.
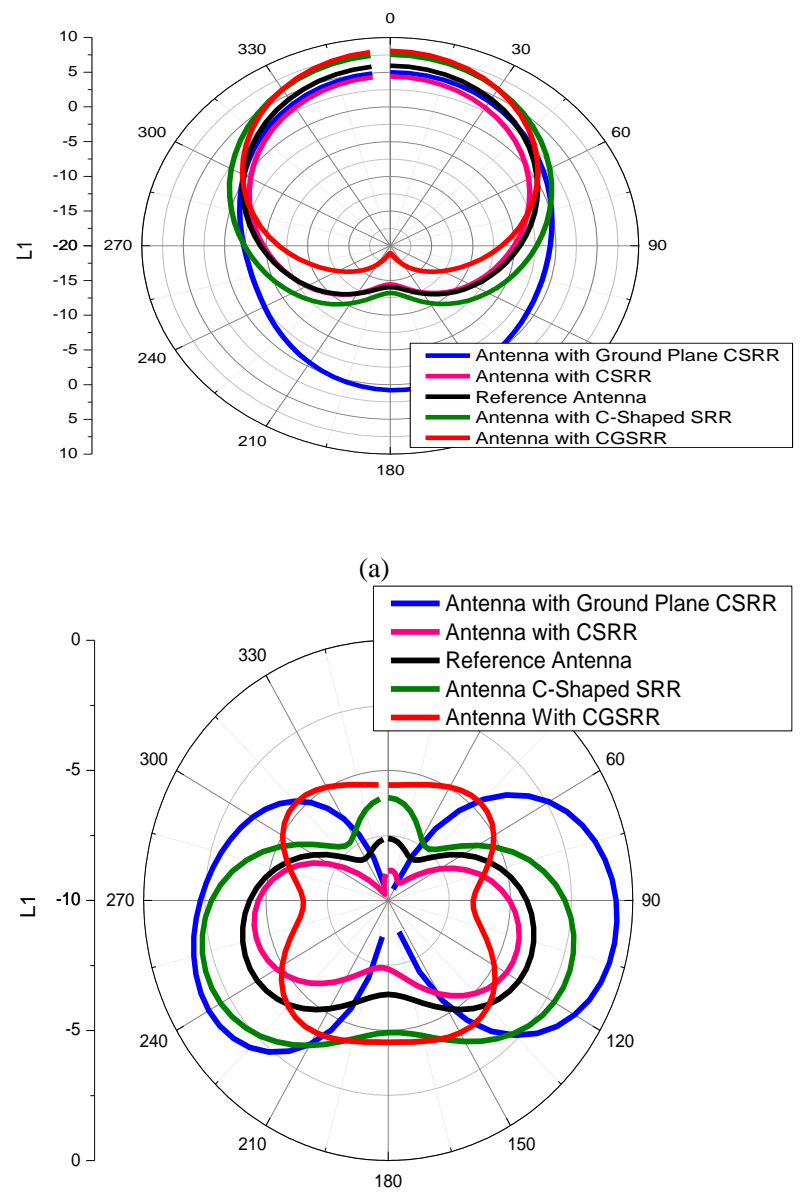

(b)

Fig. 16. Comparison of the radiation patterns of proposed antenna with the designs in [14-17] (a) E plane (b) H plane.
TABLE IV. PERFORMANCE COMPARISON OF THE PROPOSED ANTENNA WITH THE TECHNIQUES USED IN [15]-[17]

\begin{tabular}{|l|l|l|l|l|l|l|}
\hline Antennas & $\begin{array}{l}\mathbf{F r} \\
\mathbf{G H z}\end{array}$ & $\begin{array}{l}\mathbf{S 1 1} \\
\mathbf{d B}\end{array}$ & $\begin{array}{l}\text { Gain } \\
\mathbf{d B}\end{array}$ & $\begin{array}{l}\mathbf{D i r} \\
\mathbf{d B i}\end{array}$ & $\begin{array}{l}\mathbf{\eta} \\
\mathbf{\%}\end{array}$ & $\begin{array}{l}\text { Size } \\
\text { reduction } \\
\mathbf{\%}\end{array}$ \\
\hline $\begin{array}{l}\text { Reference } \\
\text { Antenna }\end{array}$ & 2.57 & -15.5 & 5.92 & 7.32 & 80 & $* *$ \\
\hline Ref [15] & 2.58 & -27 & 7.88 & 8.76 & 89 & $* *$ \\
\hline Ref [16] & 1.90 & -12.5 & 4.72 & 7.03 & 67 & 11.7 \\
\hline Ref [17] & 2.32 & -12.3 & 4.46 & 6.89 & 65 & 4.37 \\
\hline $\begin{array}{l}\text { Proposed } \\
\text { Antenna }\end{array}$ & 2.4 & -29 & 6.91 & 7.34 & 94 & 3 \\
\hline
\end{tabular}

TABLE V. Comparative Study of the Proposed TeChNique and OTHER PREVIOUS WORKS

\begin{tabular}{|c|c|c|}
\hline Antennas & Miniaturization & Performance \\
\hline Antenna With GCSRR & -- & ++ \\
\hline $\begin{array}{c}\text { Antenna With Ground } \\
\text { Plane CSRR }\end{array}$ & ++ & -- \\
\hline Antenna with CSRR & + & -- \\
\hline $\begin{array}{c}\text { Antenna with C-Shaped } \\
\text { SRR }\end{array}$ & + & + \\
\hline
\end{tabular}

Finally, it is noted from Table $\mathrm{V}$ that the proposed technique is the perfect approach because at the same time we can improve the performance and miniaturize the size of the patch antenna.

Based on this work several perspectives can be envisaged concerning the method of inclusion metamaterials in RFID antennas. It would be very interesting to realize multi-band antenna based on left-handed metamaterials more miniaturized and more efficient. Identically, another interesting perspective can be created by obtaining antenna with good frequency characteristics and with a circular polarization based on metamaterials.

\section{CONCLUSION}

This paper presents a new method to implement C Shaped SRR on the conductive surface of the rectangular patch antenna. This method is proposed to enhance the gain in the operating frequency and decrease the size of the patch antenna. In comparison with the rectangular patch antenna without metamaterials, the proposed method able to increase the antenna in terms of gain. Therefore the efficacy $\eta$ and return loss of the patch antenna are improved.

\section{ACKNOWLEDGMENT}

The authors would like to thank the team Unit of Research Circuits and Electronic Systems High Frequency of the faculty of Science Tunisia for supporting this project. 


\section{REFERENCES}

[1] D.Richards, H.Saunders and St.George, "Royal Air Force", HM Stationery office, vol 2, pp. 1939-1945, November 1953.

[2] B.Violino and M.Roberti,"The history of RFID Technology", RFID Journal, pp.1338, Jan 2005.

[3] A.Juels "RFID Security and Privacy: A Research Survey", IEEE Journal on Selected Areas in Communications, Vol. 24, Issue 2, pp. 381-394, February 2006.

[4] M.R.Rieback, B.Crispo and A.S. Tanenbaum "The Evolution of RFID Security," IEEE Pervasive Computing, Vol. 5, No. 1, pp. 62-69, JANUARY-MARCH 2006.

[5] K.V.Seshagiri, Rao, P.V. Nikitin, and S.F. Lam, "Antenna Design for UHF RFID Tags: A Review and a Practical Application", IEEE Transactions on Antennas and Propagation, Vol. 53, N ${ }^{\circ}$, December 2005.

[6] L.Yang, A.Rida, R.Vyas, and M.M. Tentzeris, "RFID Tag and RF Structures on a Paper Substrate Using Inkjet-Printing Technology", IEEE Transactions on Microwave Theory and Techniques, Vol. 55, N 12, pp. 2894-2901, December 2007.

[7] V.G Veselago, "Electrodynamics of substances with simultaneously negative electrical and magnetic properties", Sov, Phys, vol. 10, pp. 509517, February 1968.

[8] J.B.Pendry, A.J.Holden, W.J.Stewart and I. Youngs, "Extremely lowfrequency plasmons in metallic meso structures", Phys. Rev. Lett, vol. 76, pp. 4773-4776, June 1996.

[9] J. B. Pendry, A. J. Holden, D.J. $1.6 \mathrm{~mm}$, and W.J. Stewart, "Magnetism from conductors and enhanced nonlinear phenomena", IEEE Trans. Microwave Theory Tech, vol. 47,pp.2075-2084, Nov 1999.

[10] S.Naoui, L.Latrach, and A.Gharsallah, "Electrical Modelling of Split Ring Resonators Operate in the UHF band", International Conference on Computer Technologies Innovations \& Applications, Tunisia, June 14$16,2014$.

[11] R.A Shelby, D. R. Smith, S. Shultz, "Experimental verification of a negative index of refraction", Science, vol. 292, pp. 77-79, Apr. 2001.
[12] D. R. Smith, "The reality of negative refraction," Phys.World, vol. 16, pp. 23-24, June 2003.

[13] D. R. Smith, J. B. Pendry, and M. C. K. Wiltshire, "Metamaterials and negative refractive index," Science, vol. 305, pp. 788-792, Aug 2004.

[14] Y.Liu and all, "Investigation of Circularly Polarized Patch Antenna With Chiral Metamaterial", IEEE Antennas and Wireless Propagation Letters, Vol. 12, pp. 1359-1362, June 2013.

[15] M.M.Bakry, A.B. Abdel-Rahman and H.F. A. Hamed, "Metamaterials Gain and Bandwidth Improvement of Microstrip Patch Antenna using Complementary G-shape Split Ring Resonator", 31 ${ }^{\text {st }}$ National Radio Science Conference, (NRSC2014), Egypt, pp.35-40, April 28-30, 2014.

[16] M.Elsdon and O.Yurduseven, "Direct-Fed Reduced Size Patch Antenna Using Array of CSRR in the Ground Plane", Microwave and Optical Technology Letters, Vol. 57, No. 7, pp.1526-1529, July 2015.

[17] S.Naoui, L.Latrach, and A.Gharsallah, "Metamaterials Microstrip Patch Antenna For Wireless Communication RFID Technology", Microwave and Optical Technology Letters, Vol. 57, No. 5, pp 1060-1066, May 2015.

[18] Constantine A. Balanis, "Antenna Theory: Analysis and Design", 2nd edn, John Wiley \& Sons, Ltd, Chichester, ISBN:0-471-59268-4,858 pages, 1996.

[19] Constantine A. Balanis, "Antenna Theory: Analysis and Design", 3rd edn, John Wiley \& Sons, Ltd, Chichester, ISBN: 978-0-471-66782-7, 11-36, May 2005.

[20] Christophe Caloz and Tatsuo Itoh, "Electromagnetic Metamaterials: Transmission line theory and microwave applications", John Wiley \& Sons, Inc. ISBN-10: 0-471-66985-7, 2006

[21] Akhlesh Lakhtakia, Vasundara V. Varadan, and Vijay K. Varadan," Field equations, Huygens's principle, integral equations, and theorems for radiation and scattering of electromagnetic waves in isotropic chiral media", JOSA A, Vol. 5, Issue 2, pp. 175-184,1988.

[22] David A. B. Millier,"Huygens's Wave Propagation Principle Corrected", Optics Letters, Vol.16, No.18, September 15, 1991. 